\title{
Surface-micromachined Ta-Si-N beams for use in micromechanics
}

\author{
M-A Grétillat $\dagger \|$, C Linder $\ddagger$, A Dommann $\ddagger$, G Staufert $\ddagger$, \\ N F de Rooij $\dagger$ and M-A Nicolet $\S$ \\ $\dagger$ Institute of Microtechnology, University of Neuchâtel, CH-2007 Neuchâtel, \\ Switzerland \\ $\ddagger$ Institut für Mikrosystemtechnik, Neu-Technikum Buchs, CH-9471 Buchs, \\ Switzerland \\ $\S$ California Institute of Technology, Pasadena, CA 91125, USA
}

Received 12 August 1997, accepted for publication 2 December 1997

Abstract. Realization and characterization of free-standing surface-microstructures based on Ta-Si-N films are presented. Due to their significant physical and chemical properties, such ternary films are promising candidates for application in microelectromechanical devices.

\section{Introduction}

Amorphous $\mathrm{Ta}-\mathrm{Si}-\mathrm{N}$ thin films have been proven to successfully meet the requirements for use as diffusion barriers for metal/silicon contacts in microelectronics [1]. In addition, the resistivity of such Ta-Si-N films is a few hundred $\mu \Omega \mathrm{cm}$ for nitrogen concentrations less than $50 \%$ [2], thus filling the gap between metal conductors and doped polysilicon. Furthermore, the amorphous structure of this new material may hamper fatigue effects as often observed in metals. The fabrication of $\mathrm{x}$ ray amorphous $\mathrm{Ta}-\mathrm{Si}-\mathrm{N}$ microbeams using a sacrificial Al layer has been shown previously [3]. This paper describes an alternative IC-compatible process employing phosphorus-doped silicon dioxide (PSG) as a sacrificial layer. Furthermore, etching characteristics of $\mathrm{Ta}-\mathrm{Si}-$ $\mathrm{N}$ are investigated, i.e., the resistance in wet etchants as well as the patterning by dry etching. Finally, the electromechanical behaviour of $\mathrm{Ta}-\mathrm{Si}-\mathrm{N}$ beams integrated together with substrate diffusions is demonstrated.

\section{Experimental details}

The Ta-Si-N films have been deposited by reactive sputtering in an $\mathrm{Ar} / \mathrm{N}_{2}$ plasma ( $5 \% \mathrm{~N}_{2}$ partial gas pressure) employing a $\mathrm{Ta}_{5} \mathrm{Si}_{3}$ target. In order to decrease the compressive stress of the as-deposited films, annealing at $450{ }^{\circ} \mathrm{C}$ is carried out [3]. An example of a fabricated free-standing Ta-Si-N microstructure is shown in figure 1 . The PSG layers have been produced by chemical vapour deposition (CVD) at $350{ }^{\circ} \mathrm{C}$ and densified at $625^{\circ} \mathrm{C}$. A lateral etch rate of about $0.4 \mu \mathrm{m} \mathrm{min}{ }^{-1}$ is achieved for the sacrificial PSG in buffered hydrofluoric acid (BHF 7:1).

\footnotetext{
|| Phone: +41 327205 121; fax: +41 327205 711;

email: marc.gretillat@imt.unine.ch
}

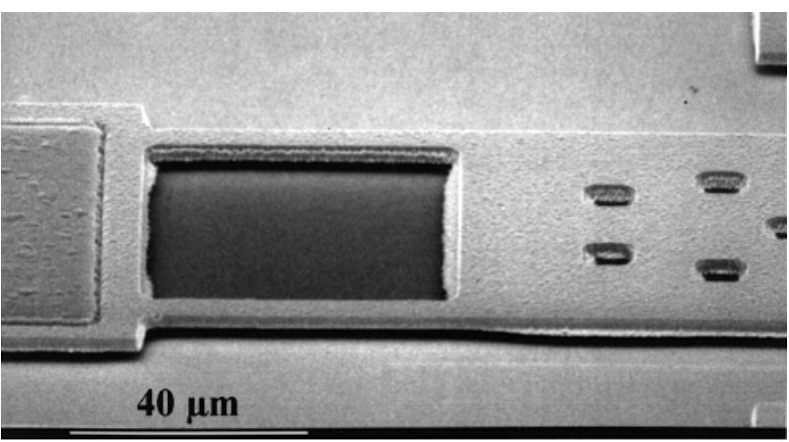

Figure 1. A SEM of a Ta-Si-N microactuator beam structure; the beam is $300 \mu \mathrm{m}$ long and $80 \mu \mathrm{m}$ wide. The underetch holes are $10 \mu \mathrm{m}$ in diameter and the tethers are $20 \mu \mathrm{m}$ wide.

Table 1. The chemical resistance of Ta-Si-N.

\begin{tabular}{ll}
\hline Chemical & Time \\
\hline BHF [7:1] & more than $60 \mathrm{~min}$ \\
$\mathrm{HNO}_{3}(100 \%)$ & at least $10 \mathrm{~min}$ \\
$\mathrm{H}_{2} \mathrm{SO}_{4}+\mathrm{H}_{2} \mathrm{O}_{2}$ & at least $10 \mathrm{~min}$ \\
$\mathrm{H}_{3} \mathrm{PO}_{4}+\mathrm{HNO}_{4}$ & \\
(aluminium etchant) & more than $100 \mathrm{~min}$ \\
\hline
\end{tabular}

As indicated in table 1 etch tests revealed that $\mathrm{Ta}-\mathrm{Si}-\mathrm{N}$ resists $\mathrm{BHF}$ (7:1) for more than one hour. This is essential for the sacrificial layer technology where etching times of this order are required. Furthermore, Ta-Si-N successfully withstands wet etching in $\mathrm{HNO}_{3}(100 \%)$ and $\mathrm{H}_{2} \mathrm{SO}_{4} / \mathrm{H}_{2} \mathrm{O}_{2}$, i.e., no thickness reduction or degradation such as strong oxidation was observed. Thus, standard cleaning and resiststripping steps using the above acid mixtures do not attack Ta-Si-N layers.

The patterning of $\mathrm{Ta}-\mathrm{Si}-\mathrm{N}$ films is usually performed 
Table 2. Ta-Si-N dry etching: process parameters and results.

\begin{tabular}{lll}
\hline Gases & $\mathrm{C}_{2} \mathrm{ClF}_{5} / \mathrm{SF}_{6}$ & $\mathrm{SF}_{6} / \mathrm{O}_{2}$ \\
\hline Mask & positive photoresist & positive photoresist \\
Pressure (mbar) & 0.1 & 0.2 \\
Power $(\mathrm{W})$ & 100 & 125 \\
Etch rate $\left(\mathrm{nm} \mathrm{min}{ }^{-1}\right)$ & 70 & 140 \\
\hline
\end{tabular}

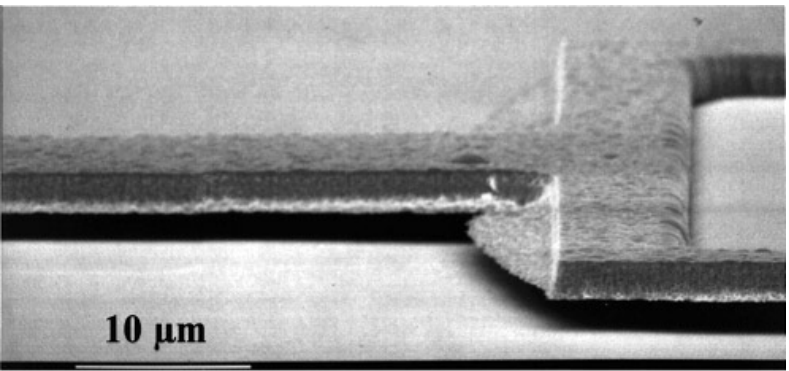

Figure 2. A SEM close-up of the anchor pad (right-hand side) of a $300 \mu \mathrm{m}$ long and $20 \mu \mathrm{m}$ wide Ta-Si-N beam actuator.

by dry etching [4]. As shown in table 2, reactive ion etching (RIE) using $\mathrm{SF}_{6} / \mathrm{O}_{2}$ and $\mathrm{C}_{2} \mathrm{ClF}_{5} / \mathrm{SF}_{6}$ gases has been applied. The chlorine/fluorine gas mixtures resulted in better uniformity than the fluorine (oxygen) gases. The sidewall profiles of a $\mathrm{Ta}-\mathrm{Si}-\mathrm{N}$ structure as etched in a $\mathrm{C}_{2} \mathrm{ClF}_{5} / \mathrm{SF}_{6}$ plasma are illustrated in figure 2 . The remaining parts at the edges can be suppressed by an appropriate overetching. Choosing appropriate process parameters for power and pressure, etch rates of more than $100 \mathrm{~nm} \mathrm{~min}{ }^{-1}$ are achieved.

\section{Application and discussion}

By adding substrate diffusions as counter-electrodes under the $\mathrm{Ta}-\mathrm{Si}-\mathrm{N}$ microbeams as sketched in figure 3, electrostatically driven prototype actuators have been built. The transfer function of these devices under vacuum has been measured with an optical interferometer. The output signal of the latter has been fed into a gainphase analyser. Figure 4 shows the characteristics for such a clamped-clamped beam. Resonance frequencies of $113 \mathrm{kHz}$ and $140 \mathrm{kHz}$ were measured for $350 \mu \mathrm{m}$ and $300 \mu \mathrm{m}$ long beams having a thickness of $2 \mu \mathrm{m}$. As can also be seen from figure 4, these devices exhibit a relatively high quality factor of about 1000 in vacuum. Thus, the resonance behaviour of the $\mathrm{Ta}-\mathrm{Si}-\mathrm{N}$ structures is promising for application in micromechanical devices such as relays [5]. Compared with polysilicon, the amorphous $\mathrm{Ta}-\mathrm{Si}-\mathrm{N}$ has similar mechanical properties but a higher electrical conductivity. In addition, a comparable lifetime is expected.

\section{Conclusion}

Free-standing Ta-Si-N microbeams, employing CVD silicon dioxide as sacrificial layer, have been demonstrated.
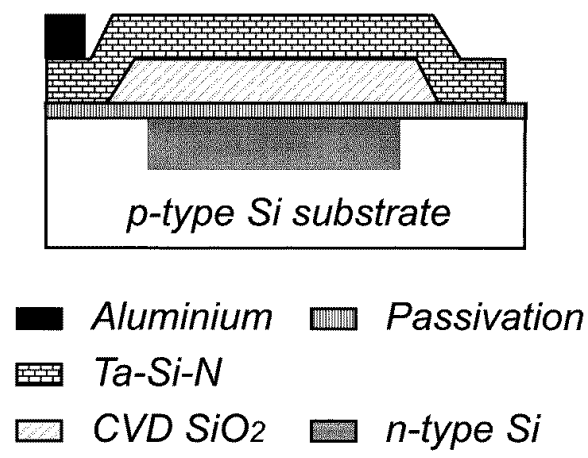

Figure 3. Schematic cross section of a surface micromachined $\mathrm{Ta}-\mathrm{Si}-\mathrm{N}$ actuator with an electrostatic drive. CVD silicon dioxide serves as the sacrificial layer.

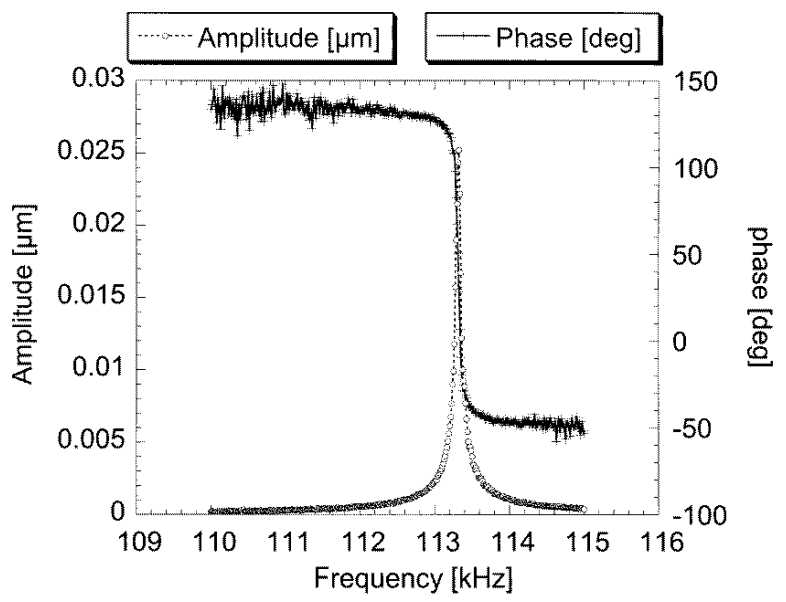

Figure 4. Measured transfer characteristic of a $350 \mu \mathrm{m}$ long beam actuator in vacuum; the resonance frequency reveals a quality factor of about 1000 .

The outstanding physical properties of the $\mathrm{Ta}-\mathrm{Si}-\mathrm{N}$ structures point out the attractiveness of this material for use in microelectromechanical components such as resonators or switches. Moreover, the resistance of Ta$\mathrm{Si}-\mathrm{N}$ to chemicals allows for application in an aggressive environment. Future work will focus on the mechanical property characterization.

\section{References}

[1] Nicolet M-A 1995 Ternary amorphous metallic thin films as diffusion barriers for Cu metallization Appl. Surf. Sci. 91 269-76 
[2] Kolawa E, Molarius J M, Nieh C W and Nicolet M-A 1990 Amorphous $\mathrm{Ta}-\mathrm{Si}-\mathrm{N}$ thin-film alloys as diffusion barrier in Al/Si metallizations J. Vac. Sci. Technol. A 8 3006-10

[3] Linder C, Dommann A, Staufert G and Nicolet M-A 1996 Amorphous metals as new materials for transducer applications Proc. 10th Eur. Conf. Solid-State Transducers (Eurosensors $X$ ) No C2-2
[4] McLane G F, Casas L, Reid J S, Kolawa E and Nicolet M-A 1994 Reactive ion etching of TaSiN diffusion barrier in $\mathrm{CF}_{4}+\mathrm{O}_{2}$ J. Vac. Sci. Technol. B 12 2352-5

[5] Grétillat M-A, Thiébaud P, de Rooij N F and Linder C 1994 Electrostatic polysilicon microrelays integrated with MOSFETs IEEE Micro Electro Mech. Syst. Workshop pp 97-101. 